\title{
Environmental beliefs and their role in environmental behaviours of undergraduate students
}

\author{
Robert Inkpen ${ }^{1} \cdot$ Brian Baily ${ }^{1}$ (I)
}

Published online: 29 October 2019

(C) The Author(s) 2019

\begin{abstract}
A survey of the environmental world-views of undergraduate students found that their views of the environment could be reduced, as had been found by Price et al. (J Environ Psychol, 37, 8-20 2014) into the 'as elastic' and the 'environment as ductile'. The 'environment as elastic' summarizes a range of views that focus on the unpredictable nature of the environment and its ability to recover from the impact of human activities. Unlike Price et al. (J Environ Psychol, 37, 8-20 2014), however, the basis of the 'environment as elastic' view is solidly based on a fatalistic/non-fatalistic world-view of this age group. The survey suggests that the likelihood of individuals demonstrating environmentally aware behaviour was strongly correlated with their environmental world-view and how their general ideological word views is conditioned by their political alignment. There was, however, a limited range of behaviours that even environmentally aware undergraduates were prepared to take now and into the future and these were correlated with their concern to adopt what might be considered to be conveniently successful life styles.
\end{abstract}

Keywords Environmental perception $\cdot$ Environmental behaviour $\cdot$ World-views $\cdot$ Political word views

\section{Introduction}

According to the United Kingdom 25-year environment plan (HM Government 2018) the scale of human impact on the planet has never been greater than it is now. The Living Planet Report 2018 states that since 1970, 60\% of mammals, birds, fish and reptile's species have declined (WWF 2018). Climate change, habitat loss, increases in natural hazards, over-consumption and non-circular resource use are just a few of the many challenges facing policy makers and the wider population. It is clear that any solutions to these problems will require a significant amount of actions by individuals, voluntary or otherwise, to change environmental behaviours. The extent of this problem is illustrated in the British Social Attitudes Survey (Philips et al., 2018) where $95 \%$ of people questioned think that climate change is probably happening but where people gave an average score of 4.4 out of

Electronic supplementary material The online version of this article (https://doi.org/10.1007/s13412-019-00570-z) contains supplementary material, which is available to authorized users.

Brian Baily

brian.baily@port.ac.uk

1 Department of Geography, University of Portsmouth, Buckingham Building, Lion Terrace, Hampshire PO1 3HE, UK
10 for the chances that limiting their own energy use would reduce climate change.

The nature and extent of the problems facing the environment are relatively well known but it could be argued that there is a disconnect between individual responsibility and environmental behaviour, a separation that represents a significant challenge for environmental management at all levels (Johnstone and Tan 2015). The expectation that increased environmental concern should lead to an increase in environmental actions (e.g. McCarty and Shrum 1994), grounded in the value-attitude behaviour perspective of such research has not necessarily been confirmed by researchers. It can be argued that there is often a clear gap between the level of environmental concern and the subsequent actions implying that relationships between environmental concerns and actions is more complex than might initially appear (see for example Blake 1999; Kollmus and Agyeman 2002; Eilam and Trop 2012).

As pointed out by Rhead et al. (2015) understanding the nature of environmental concerns is essential for understanding how society engages with environmental problems. Within the context of climate change, research has highlighted clear differences in attitudes towards the environment based on world-views as well as education levels, gender and age. Previous research has shown that climate scepticism was higher from respondents with a more traditional background, 
politically conservative views and lower socio-economic groupings (Poortinga et al. 2011). Whitmarsh (2011) found that scepticism in relation to climate change was strongly influenced more by environmental and political values rather than by education or knowledge.

Barr (2007), within the realm of waste management, noted that environmental behaviours are broadly attributed to three groups of independent variables: situational variables; environmental values and psychological factors.

Within this spectrum of attitudes, cultural values and beliefs can be seen to be a strongly influencing factor on people's concerns and actions. Cultural beliefs and values are essential in understanding how people react to environmental challenges. Understanding the impact of cultural values and beliefs enables us at least in part to interpret why for example, four in ten Americans say that climate change will have a little or no impact on them personally (Jones et al. 2014). It can be argued that cultural responses filter our attitudes to environmental risk and associated actions. The measurement of cultural values and beliefs is well established and according to Taras et al. (2010) expanded significantly after Hofstede's "Culture's Consequences" in 1980.

This research explores the environmental world-views of undergraduate students and examines the likelihood of individuals demonstrating environmentally aware behaviour and to what extent this correlates with their environmental world-view. In addition, this research examines how their general ideological word-views is conditioned by their political alignment. Importantly this is the first research that examines how the various elements influence the environmental behaviours of the British students surveyed.

\section{Theoretical background}

Views about the nature of evidence, the magnitude of environmental issues and the acceptability of solutions are all affected by the framework of values and beliefs held by individuals (Kahan 2010; Kahan et al. 2012). Individuals are deeply embedded within the cultural frameworks which generate the environmental issues that require actions to alleviate (Adger et al. 2013) and so identification and positioning of individuals within these frameworks is an essential aspect of the analysis of an individual's perception of environmental risk (Kahan 2010). Identifying and classifying an individual's belief and value system in relation to issues of environmental risk can then help in understanding how individual's interpret and react to evidence and solutions. Similarly, the consistency of an individual's world-view can be analysed by comparing their response to different types of issues relative to their belief and value systems. Inconsistency in attitudes towards issues would imply that the belief and value system of an individual can exhibit a degree of flexibility depending on the nature of the issues being considered. This would imply that strategies that are effective for encouraging actions on one issue are not necessarily transferable to other issues.

This research project uses the 'myths of physical reality' framework developed in cultural theory by Douglas and Wildavsky (1982) and extended to environmental risks by Schwarz and Thompson (1990) to identify world-views of undergraduates. Individuals will be classified and located within the four 'world-views' (hierarchical, egalitarian, individualistic and fatalistic; Table 1) along the grid/group axes developed by Douglas (1978). Hierarchical world-views see nature as a robust system if managed correctly. Under this world-view environmental problems can be controlled it is argued by robust regulation and expert knowledge. Egalitarian world-views believe that the use of nature must be balanced between ours needs and the needs of future generations. Within this world-view limiting our own behaviour is seen as the best way of reducing environmental problems. People with individualistic world-views see nature as a robust system. This group also tend to believe that environmental problems can be solved by technical solutions. The final category is the fatalistic group who view nature as an unpredictable system. This group as the name suggests are indifferent to environmental problems and think little can be done to solve these issues.

Recent evidence from Price et al. (2014) suggests that such cultural biases associated with environmental issues may be simplified in terms of individual's position on the group axis alone (hierarchical/egalitarian world-view). The problem of relative lack of clarity in terms, however is something that needs to be considered when interpreting the data below. Milford and Duclitt (2010) and Schultz et al. (2005) noted that key terms such as 'environmental attitudes' and 'environmental concerns' and environmental world-view are usually poorly defined. Whilst some have viewed pro-environmental behaviour as altruistic (DeGroot and Steg 2009), such behaviour can also have a pro-social aspect, where such behaviour is seen by the individual as advancing or being indicative of their social status. Within this research, we define environmental concerns as an individual's worries in relation to a range of issues including resource depletion, habitat destruction and global warming. Environmental attitudes influence environmental behaviours and are as defined by (Milfont 2007) as a psychological tendency expressed by evaluating the natural environment with some degree of favour or disfavour. Within this research, we focus on the environmental worldview through the lens of a set of questions developed by Price et al. (2014) and define environmental behaviour only within the terms of the specific behaviours in the survey questions.

This research will assess if the simplification of worldviews into the two identified by Price et al. (2014) is present within a United Kingdom (UK) based undergraduate student population sampled in this research. The two views are the 'environment as elastic' where 'the ecosystem is described as resilient and able to bounce back from both damage and efforts 
Table 1 Four world views of Price et al. 2014

\begin{tabular}{ll}
\hline Myth of nature & Characteristics \\
\hline Egalitarian & Use of nature must be balanced between ours needs and the needs of future generations. \\
& Attempts to control environmental problems by limiting own behaviour. \\
Hierarchist & Nature as robust system if managed correctly. \\
& Environmental problems can be controlled by robust regulation and expert knowledge. \\
Individualist & $\begin{array}{l}\text { Nature seen as a robust system. } \\
\text { Environmental problems can be solved by technical solutions. } \\
\text { Fatalist }\end{array}$ \\
& Nature as unpredictable. \\
& Indifference to environmental problems. \\
\hline
\end{tabular}

to protect it' (Price et al. 2014, p. 13). The other world-view is 'environment as ductile'. Where 'the ecosystem is described as altered by human activity and unable to bounce back from damage or efforts to protect it' (Price et al. 2014, p. 13).

Additionally, we will assess if this simplification can be used to explain any inconsistency between concerns about the threats from environmental issues and their proenvironmental behaviours. Consistency in world-views across general social and political issues will also be explored as recent evidence from (Coppock and Green 2017) suggests that individuals tend to compartmentalize their attitudes to issues meaning that concern and actions about environmental issues will be limited to that issue alone. It is suggested that this compartmentalization will result in what seem to be inconsistency in the attitudes of individuals to a range of issues and policies. From a policy perspective this would mean that a 'one size fits all' set of strategies for encouraging actions on a range of issues would not be appropriate.

\section{Research questions}

This research focuses on three main research questions:

- Is there consistency in an individual's environmental world-view? Can it be adequately described by the 'nature as elastic' and 'nature as ductile' classification proposed by Price et al. (2014)?

- Are the environmental world-views of individuals associated with their level of environmental concern and with the level of their environmental actions?

- Are the environmental world-views of individuals distinct and separate from the political views of individuals?

\section{Methodology}

\section{Participants}

This survey was conducted between January-February 2018 and involved university-wide recruitment of undergraduate students (survey questions can be found in Appendix 1). Students from the United Kingdom were selected as the group for this case study as they were seen as the group of potential 'young professionals' who may go on to influence policy and practice at all scales. In the United Kingdom, the Brexit referendum has suggested clear differences of opinion between particular groups in relation to amongst other things generational and educational lines (Hobolt 2016). Students are not necessarily a homogenous population, just like the wider population of young people. Within this sample there was a dominance of Science-based students (64\%), with a minority of Humanitiesbased students (36\%), but the overwhelming majority $(80 \%)$ had had some form of education in climate change at school and virtually every course within the university considered environmental change as part of its curriculum. In this sense the student population selected is likely be, in theory, better informed about the nature and impacts of environmental change. The overwhelming majority of participants were from southern England, London and the home counties (85\%), with a minority from the Midlands or eastern England (20\%). This relatively narrow spatial distribution meant that there were likely to be little variation in perceptions due to regional influences.

Recruitment was voluntary and involved students responding to an inter-departmental email (with a total pool of approximately 1500 students) and then completion of an online survey. A total of 152 undergraduates replied (about a $10 \%$ response rate). Undergraduate students were selected as this restricted the variation in age and education level of respondents removing these as potential explanatory factors. Instead, the limited age and educational range meant that the respondents reflected the environmental world-views of individuals that were relatively well educated and, given the environmental awareness embedded in the national curriculum as noted above, should be relatively interested in responding to and undertake environmental friendly behaviour in the future. This survey, therefore, addressed the environmental world-views of a section of the population likely to be influential in the success or failure of environmental policies in the future. The breakdown of the respondents provided a good coverage of gender 
(52.8\% female and $47.2 \%$ male) and different stages of their university education (Year $1-36.4 \%$, Year 2$33.6 \%$, Year 3-30\%).

The results from the questionnaire data were then deferentially tested through factor analysis, Cronbach Alpha and Kruskal Wallis.

\section{Quantifying environmental world-views}

As in Price et al. (2014) a pool of 40 items were used to quantify cultural environmental world-views (Appendix 1). We gratefully acknowledge both the detailed testing and critical discussion of the questions undertaken by these authors as well as the authors upon whose work they built their series of questions (Kahan et al. 2010; Dake 1992; Triandis 1996; Dunlap et al. 2000, and Steg and Sievers 2000). For each world-view there were five items that described the beliefs about human relationships to the natural environment and five items that described policy solutions for managing the natural environment. The individualistic worldview, for example, frames the environment as able to cope with disturbances and able to recover reflected in the question 'The natural environment is strong and can easily adapt to human activity' for which a strongly agree response would equate to a highly individualistic world-view and so score a 5. Likewise, such a world-view is aligned to view certain policies as appropriate when dealing with the environment, so responding 'strongly agree' to the question 'Economic markets are more than capable of managing the natural environment sustainably' reflects such an individualistic world-views and would be scored as 5 .

Participants were asked to indicate their level of agreement with each on a 5-point scale. The coding was designed so that the four world-views were scored 5 on the relevant beliefs and policy questions associated with each. This should mean that a consistent hierarchical world-view scored a total of 50 on the two questions associated with hierarchal beliefs and policies, but only 10 on the two questions focused on the individualistic world-view. The scores for each answer were then used in a factor analysis of the responses of all those surveyed enabling each individual to be located within factor analysis space.

\section{Quantifying environmental behaviour}

Questions on environmental behaviour mirrored those used by Lynn (2014) in an analysis of determinates of proenvironmental behaviour. Questions about environmental behaviour focus on simple actions that individuals could take now to alleviate environment issues and on how individuals expect their future behaviours to impact the environment.

\section{Consistency of environmental world-views}

The 40 world-view questions were subject to exploratory factor analyses (maximization of the sum of variance squared on the loadings) using Minitab 17.0 and SPSS 23.0 to identify the underlying structure of the responses. The responses were coded from 1 (strongly disagree) to 5 (strongly agree) with the view expressed in the question. This means that a high score on questions related to hierarchical and egalitarian views reflects agreement with these views, whilst a high score on the individualist and fatalist questions reflects agreement with these views. It might be expected that a committed environmentalist would tend to score high on the hierarchical and egalitarian questions and low on the individualist and fatalist questions.

Before undertaking factor analysis of the responses a series of Cronbach alpha tests were run of each of the sets of questions designed to assess hierarchical, egalitarian, individualist and fatalist world-views (Table 2). The Cronbach alpha quantifies the reliability or internal consistency of a set of test items. It is not a measure of the dimensionality of these items but rather provides an indication of whether the items provide a consistent and strong measure of the underlying concept the items are meant to assess. The scale can vary from 0 to 1 with 1 indicating perfect covariation amongst all the test items and 0 indicating total independence of the test items. The closer to 1 the Cronbach alpha is then the more this suggests that the test items used are likely to be measuring the same concept. Although there is no agreed standard for what is an acceptable Cronbach alpha value, values as 0.5 can be considered acceptable, although Tavakol and Dennick (2011) suggest it may be more appropriate to suggest values in the range $0.75-0.90$ fit this category. Low Cronbach alpha values can be associated with having a limited number of questions or poor interrelatedness between the items used. Although all values in Table 2 are above 0.5 , the values in the table suggest that the division of questions into 5 question blocks to identify specific aspects of environmental world-views, e.g. hierarchical-environmental and hierarchical-political may be too

Table 2 Cronbach alpha values for world view questions

\begin{tabular}{ll}
\hline World View & Cronbach Alpha \\
\hline Hierarchical Environment & 0.61 \\
Hierarchical Political & 0.62 \\
Egalitarian Environment & 0.59 \\
Egalitarian Political & 0.58 \\
Individualist Environment & 0.69 \\
Individualist Political & 0.59 \\
Fatalist Environment & 0.76 \\
Fatalist Political & 0.80 \\
Hierarchical & 0.69 \\
Egalitarian & 0.69 \\
Individualist & 0.74 \\
Fatalist & 0.79 \\
Hierarchical/Egalitarian & 0.79 \\
Individualist/Fatalist & 0.85 \\
\hline
\end{tabular}


fine a division to provide a consistent measure of that underlying concept. Combing sets of questions to identify more general world-views such as hierarchical or individualistic, produce higher values suggesting that more questions may refine and improve the consistency of the measure.

Having assessed the internal consistency of the response to questions about environmental world-views, the underlying structuring or dimensionality of these views was explored using factor analysis. Exploratory factor analysis (maximum likelihood extraction with oblimin rotation) identified the underlying structure in the data. Twelve components have eigenvalues above 1 that explained $18.2 \%, 8.8 \%, 6.3 \%, 5.0 \%$, $4.8 \%, 4.1 \%, 4.0 \%, 3.8 \%, 3.5 \%, 2.9 \%, 2.6 \%$ and $2.5 \%$ of the variance respectively. Appendix 1 provides details of this initial exploratory analysis. As in Price et al. (2014), this initial analysis provided no clear set of patterns with many item loading on several factors. Inspection of the scree-plot and applying Cattell's (1966) and Ledesma et al. (2015) criteria, the plot clearly flattens after Factor 3 although the clear break may be associated with Factors 2 or 3. A further exploration of a three and two component solution was undertaken. The results of the three component solution showed no clear patterns except for some items relevant to fatalistic world-views having scores of 0.5 or greater. The pattern and structure factor loadings of two component solution, as presented in Table 3, did produce a relatively simple structure with most of the items substantially loading on only one axis. Identification of this simple pattern meant that the two component solution was used for analysis. Fatalistic items loaded positively on Factor 1, whilst hierarchical and egalitarian items loaded positively on Factor 2 . There is a moderate negative correlation between the factors $(r=-0.200, n=40)$.

Factor analysis was used on the responses of individuals in perceptions survey to determine the presence of any underlying factors within the data. Factors scores for Factors 1 and 2 were then assigned to each individual 1 participant based on their responses to the survey. The relationship between an individual's factor scores and their environmental concerns and behaviour was then assessed using the non-parametric Kruskal-Wallis test. This test was used, rather than correlation analysis, as an individual's environmental concerns and behaviours were scored on a Likert 5-point scale and correlation analysis would have resulted in a large number of ties.

\section{Quantifying contextual information}

Additional contextual information about an individual was collected using the same questions as used in the British Election Study (http://www.britishelectionstudy.com/) which meant that the nature of the student population could be compared nationally to assess how representative the political views of this sample were of the UK population of this age range as a whole.

\section{Results}

\section{Consistency of environmental world-views}

Comparison of the items with loadings on components 1 and 2 above 0.5 (Table 3 ) with the items identified by Price et al. (2014) as significant items (Table 4) suggests that the different items construct the factors in this study. In particular, the dominance of fatalistic items in Factor 1 differs greatly from the factors found by Price et al. (2014). In their analysis the sample of 290 individuals from across Australia represented the general population and there was a much greater importance attached to individualistic items for Factor 1 and for a greater range of hierarchical and egalitarian items contributing to Factor 2. This research suggests that for the age group surveyed there is certainly still merit in dividing environmental world-views into the 'environment as elastic' and the 'environment as ductile' but that the basis of these world-views may be subtly different from that of the general population as identified by Price et al. For Factor 1 the fatalistic items and single individualistic item all refer to policy for managing the environment rather than beliefs about human relationships to the environment. For Factor 2 all the key items refer to beliefs about human relationships to the environment and recognize that the environment is in a delicate balance that requires careful management. This suggests that the two axes represent two distinct aspect of an individual's beliefs about the environment, Factor 1 what can be done (or not) about the environment and Factor 2 what the nature of the environment is.

Factor 1 can still be described as the 'environment as elastic' as it is firmly based on the right of the individual to choice, but this is within a context of the environment itself being seen as fragile with any one individual unable to alter the trajectory of environmental degradation. Factor 2 can still be described as the 'environment as ductile' as there is still a focus on the environment as requiring human protection because of its fragility through organizations and expert knowledge.

\section{Relationship between environmental world-views and environmental concerns and behaviour}

Each individual respondent was assigned loading values for both Factors 1 and 2 based on their survey responses to their world-view questions. A correlation between individual factor scores of -0.254 (statistically significant at $\alpha=0.01$ ) suggests that individuals have consistent and divergent sets of beliefs about the environment and its management that the items in the survey have identified. Figure 1 plots individual factor scores for each factor which suggests that although generally individuals who score high on Factor 1 score low on Factor 2 and vice versa there are a number of individuals who score 
Table 3 Pattern and structure matrix for maximum likelihood factor analysis with direct oblimin rotation of two factor solution for surrey items on world views following the method of Price et al. (2014)

\begin{tabular}{|c|c|c|c|c|c|c|}
\hline \multirow[b]{2}{*}{ Item } & \multirow{2}{*}{$\begin{array}{l}\text { Pattern } \\
1\end{array}$} & \multirow{2}{*}{$\begin{array}{l}\text { Coefficients } \\
2\end{array}$} & \multirow{2}{*}{$\begin{array}{l}\text { Structure } \\
1\end{array}$} & \multirow{2}{*}{$\begin{array}{l}\text { Coefficients } \\
2\end{array}$} & \multicolumn{2}{|c|}{ Communalities } \\
\hline & & & & & Initial & Extracted \\
\hline HIER-ENV1 & -0.05 & 0.60 & -0.17 & 0.61 & 0.56 & 0.38 \\
\hline HIER-ENV2 & 0.19 & 0.08 & 0.17 & 0.04 & 0.33 & 0.04 \\
\hline HIER-ENV3 & -0.19 & 0.60 & -0.14 & 0.61 & 0.68 & 0.37 \\
\hline HIER-ENV4 & 0.03 & 0.69 & -0.11 & 0.68 & 0.65 & 0.47 \\
\hline HIER-ENV5 & 0.19 & 0.17 & 0.16 & 0.13 & 0.36 & 0.05 \\
\hline HEIR-POL1 & -0.29 & 0.42 & -0.37 & 0.48 & 0.47 & 0.31 \\
\hline HIER-POL2 & -0.42 & 0.37 & -0.12 & 0.38 & 0.37 & 0.14 \\
\hline HIER-POL3 & -0.21 & 0.32 & -0.27 & 0.36 & 0.43 & 0.17 \\
\hline HIER-POL4 & 0.13 & 0.38 & -0.21 & 0.41 & 0.46 & 0.18 \\
\hline HIER-POL5 & 0.09 & 0.33 & 0.02 & 0.32 & 0.55 & 0.11 \\
\hline EGAL-ENV1 & 0.19 & 0.13 & 0.16 & 0.09 & 0.30 & 0.04 \\
\hline EGAL-ENV2 & 0.04 & 0.57 & -0.08 & 0.56 & 0.52 & 0.32 \\
\hline EGAL-ENV3 & 0.06 & 0.21 & 0.15 & 0.20 & 0.42 & 0.04 \\
\hline EGAL-ENV4 & -0.06 & 0.46 & -0.15 & 0.47 & 0.49 & 0.22 \\
\hline EGAL-ENV5 & 0.06 & 0.58 & -0.06 & 0.57 & 0.50 & 0.33 \\
\hline EGAL-POL1 & -0.09 & 0.47 & -0.18 & 0.49 & 0.50 & 0.25 \\
\hline EGAL-POL2 & -0.21 & 0.39 & -0.29 & 0.43 & 0.53 & 0.23 \\
\hline EGAL-POL3 & -0.23 & 0.36 & -0.30 & 0.40 & 0.40 & 0.21 \\
\hline EGAL-POL4 & 0.09 & 0.25 & 0.04 & 0.20 & 0.55 & 0.06 \\
\hline EGAL-POL5 & -0.02 & 0.22 & -0.07 & 0.22 & 0.49 & 0.05 \\
\hline IND-ENV1 & 0.33 & -0.41 & 0.41 & -0.35 & 0.59 & 0.32 \\
\hline IND-ENV2 & 0.34 & -0.37 & 0.42 & -0.47 & 0.54 & 0.30 \\
\hline IND-ENV3 & 0.25 & -0.31 & 0.31 & -0.36 & 0.52 & 0.19 \\
\hline IND-ENV4 & 0.40 & -0.20 & 0.44 & -0.28 & 0.51 & 0.23 \\
\hline IND-ENV5 & 0.33 & -0.31 & 0.39 & -0.38 & 0.58 & 0.25 \\
\hline IND-POL1 & 0.03 & -0.13 & -0.01 & -0.12 & 0.46 & 0.02 \\
\hline IND-POL2 & 0.50 & -0.23 & 0.55 & -0.33 & 0.58 & 0.35 \\
\hline IND-POL3 & 0.29 & -0.14 & 0.32 & -0.20 & 0.50 & 0.12 \\
\hline IND-POL4 & 0.46 & -0.13 & 0.49 & -0.22 & 0.49 & 0.25 \\
\hline IND-POL5 & 0.45 & -0.01 & 0.46 & -0.10 & 0.46 & 0.21 \\
\hline FAT-ENV1 & 0.29 & -0.01 & 0.29 & -.06 & 0.51 & 0.09 \\
\hline FAT-ENV2 & 0.27 & -0.17 & 0.30 & -0.17 & 0.37 & 0.12 \\
\hline FAT-ENV3 & 0.46 & 0.04 & 0.45 & -.05 & 0.66 & 0.21 \\
\hline FAT-ENV4 & 0.35 & -0.15 & 0.38 & -0.05 & 0.64 & 0.15 \\
\hline FAT-ENV5 & 0.48 & -0.02 & 0.38 & -0.22 & 0.48 & 0.17 \\
\hline FAT-POL1 & 0.65 & -0.12 & 0.67 & -0.25 & 0.69 & 0.47 \\
\hline FAT-POL2 & 0.79 & 0.07 & 0.78 & -0.09 & 0.71 & 0.61 \\
\hline FAT-POL3 & 0.50 & 0.05 & 0.49 & -0.05 & 0.55 & 0.24 \\
\hline FAT-POL4 & 0.70 & -0.11 & 0.70 & -0.15 & 0.63 & 0.49 \\
\hline FAT-POL5 & 0.69 & 0.09 & 0.67 & -0.05 & 0.67 & 0.46 \\
\hline
\end{tabular}

bold indicates values over $+/-0.5$, consistent with the Price et al (2014) high on both factors producing a curvilinear trend in the data. Reconciling these views is difficult but it may reflect an acceptance of the unpredictability and uncertainty involved in trying to manage the environment but with a belief that the environment itself is inherently unstable and only understood through expert analysis. In general, however, the two factors do seem to characterize two distinct sets of environmental views, that could be caricatured as one where the environment is unmanageable and likely to recover anyway and so we do not need experts to manage it as they cannot (high scores on Factor 1 and low scores on Factor 2). Opposed to this is the environment view that the environment can be managed, 
Table 4 Pattern loadings and associated questions

Pattern Loadings Question

Factor 1

IND-POL2

FAT-POL1

FAT-POL2

FAT-POL3

FAT-POL4

FAT-POL5

Structure Loadings

IND-POL2

FAT-POL1

FAT-POL2

FAT-POL4

FAT-POL5
Factor 2

Individuals should have freedom of choice regardless of the environmental impacts

Ultimately, there is nothing individuals can do to manage or change the natural environment

Doing nothing is the most rational strategy for managing the natural environment

Attempts to manage the natural environment usually end in failure

Environmental rules and regulations are just ways for authorities and environmentalist to control individuals There is no point in wasting time, energy and resources on trying to manage the natural environment

EGAL-ENV2 If the balance of the natural environment is upset the whole system will collapse

EGAL-ENV5 The natural environment is fragile and the balance can be easily upset

Individuals should have freedom of choice regardless of the environmental impacts

Ultimately, there is nothing individuals can do to manage or change the natural environment

Doing nothing is the most rational strategy for managing the natural environment

Environmental rules and regulations are just ways for authorities and environmentalist to control individuals

There is no point in wasting time, energy and resources on trying to manage the natural environment

HIER-ENV1 The natural environment will become unstable if humans exceed the limits identified by experts

HIER-ENV3 If we push the natural environment beyond what it can cope with there will be no turning back

HIER-ENV4 When pushed beyond the limits identified by experts the natural environment will not recover

EGAL-ENV2 If the balance of the natural environment is upset the whole system will collapse

EGAL-ENV5 The natural environment is fragile and the balance can be easily upset particularly through appropriate experts, and that a key reason effective management is possible is because the environment is in a delicate balance (scores low on Factor 1 and high on Factor 2). Using individual scores on these two factors it is possible to analyse how these environmental views affect environmental behaviours, lifestyles and if they reflect broader political views of individuals.
Although the scores could be correlated with the responds to specific questions about environmental behaviour, it should be remembered that the questions tended to use a Likert 5-point scale in asking for responses. Although the resultant large number of ties for correlation analysis can be accounted for within the statistical calculation, this study compared medians scores using the non-

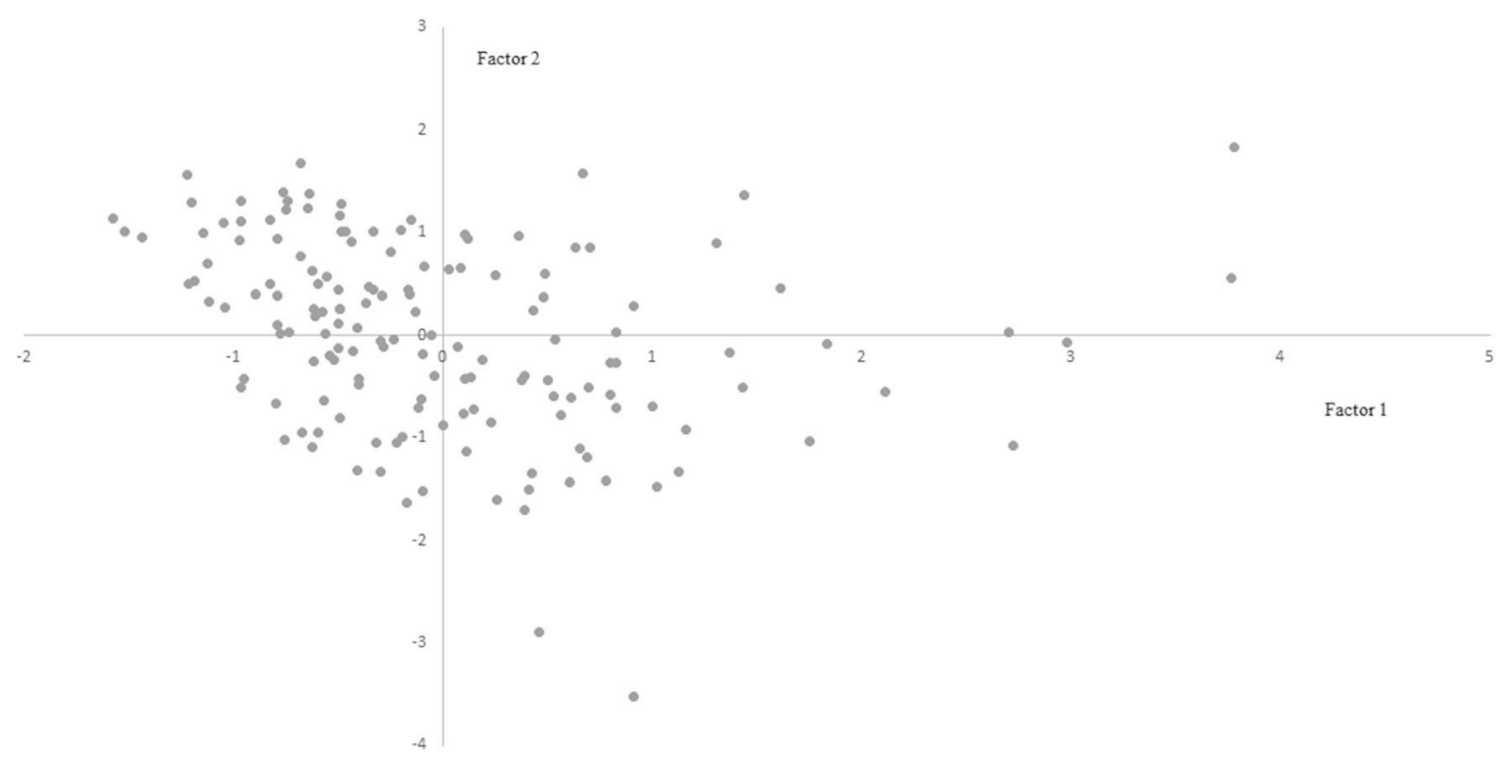

Fig. 1 Scatter plot showing Factor 1 and Factor 2 
parametric Kruskal Wallis test, a non-parametric equivalent of analysis of variance, to analyse if the median value for each factor changed with change in the likelihood of specific behaviours, lifestyles or political views (Table 5). This enabled the direction of change in median values with changing response to be analysed.

Table 5 Environmental behaviours, lifestyle and political views with the relevant factor scores

\begin{tabular}{|c|c|c|}
\hline & Factor 1 & Factor 2 \\
\hline \multicolumn{3}{|l|}{ Environmental Behaviours } \\
\hline Climate Change Education & 15.52 & 8.98 \\
\hline TV On & 2.08 & 1.30 \\
\hline Lights On & 7.33 & 3.80 \\
\hline Tap On & 9.57 & 2.39 \\
\hline Clothes On & 0.74 & 3.44 \\
\hline Packing & 4.55 & 10.65 \\
\hline Recycle Paper & 3.34 & 7.26 \\
\hline Own ag & 5.94 & 3.31 \\
\hline Bus & 3.75 & 1.90 \\
\hline Walk & 0.40 & 1.70 \\
\hline Car Share & 4.55 & 10.53 \\
\hline \multicolumn{3}{|l|}{ Lifestyle } \\
\hline Green Life & 4.83 & 13.21 \\
\hline Public Transport & 3.58 & 4.41 \\
\hline Children Green Education & 16.78 & 11.67 \\
\hline Environmental Products & 7.75 & 7.63 \\
\hline Governments Cooperate & 3.63 & 3.92 \\
\hline \multicolumn{3}{|l|}{ Political Views } \\
\hline Voting Conservative & 5.38 & 7.52 \\
\hline Voting Labour & 9.84 & 12.04 \\
\hline Voting Liberal Democrat & 2.24 & 7.16 \\
\hline Voting Green & 18.34 & 14.04 \\
\hline Voting Others & 0.35 & 5.56 \\
\hline Public Cuts & 5.97 & 9.17 \\
\hline NHS Cuts & 1.96 & 11.86 \\
\hline Education Cuts & 1.17 & 3.59 \\
\hline Budget Deficit & 2.99 & 5.33 \\
\hline Tax and Spend & 12.30 & 5.04 \\
\hline Welfare Benefits & 2.97 & 5.90 \\
\hline Private Companies & 0.69 & 4.39 \\
\hline Environmental Protection & 23.16 & 26.90 \\
\hline Attention to Politics & 4.06 & 2.10 \\
\hline Equality of Minorities & 10.48 & 6.02 \\
\hline Stiff Sentences & 5.64 & 6.64 \\
\hline Big Business & 11.31 & 7.92 \\
\hline Income Redistribution & 0.89 & 10.14 \\
\hline Fair Share & 2.31 & 4.46 \\
\hline Obey & 1.62 & 0.46 \\
\hline
\end{tabular}

In italics indicates significant at $95 \%$ level and bold indicates significant at $99 \%$ level

\section{Environmental behaviours and lifestyles}

Exploring the responses using the Kruskal Wallis test, there are only a limited number of environmental behaviours where the median value varies significantly as responses change. Simple behaviours such as turning lights and taps off do vary with response on Factor 1 with the median decreasing as the environmentally friendly behaviour becomes less frequent. On Factor 2 the median values for considering packaging before purchase and car sharing increase as the likelihood of the behaviour increases. This suggests that simple environmental behaviours are related to environmental world-views but associated with Factor 1 and an individual's non-fatalistic view of management of the environment. The relative lack of significance changes in median values associated with environmental behaviours for Factor 2 suggests that the individual's belief about the stability of the environment does not affect their behaviour. For lifestyle questions, the Krusakl Wallis test identifies the intention to educate children to be environmentally friendly and the intention to lead a green life as future intentions that increase in likelihood as Factor 2 scores increase.

\section{Environmental world-views and political views}

Table 5 highlights that there is a relatively small number of statistically significant changes in median values for each factor as responses change in reply to political questions. In terms of likelihood of voting Green there is a clear and consistent change in median values, Factor 1 values decreasing with increasingly likelihood to vote Green and Factor 2 values increasing. A similar trend for Factor 2 median values can be identified with the likelihood of voting Labour, but for Factor 1 there is statistically significant variability in the median values but it does not change consistently with likelihood of voting Labour. Interestingly, there is no significant variation in median values for each factor with likelihood of voting Conservative.

For wider policies that reflect political positions, Factor 2 has statistically significant trends in increasing median values as responses change for increasing belief that NHS cuts have gone too far and for an increasing belief in environmental protection having not gone far enough, Similarly, the median values for Factor 2 show a statistically significant decrease as the belief that big business does not exploit people increases and as the belief that it is not government's responsibility to redistribute income increases. For Factor 1, the pattern of statistically significant trends in median values is more difficult to discern. There is variability in the medians for responses to big business and exploitation and to the tax or spending question but they have no consistent direction. For environmental protection there is a decrease in the median value as the belief in environmental protection having not gone far enough 
increases, a pattern consistent with changes in the median values for Factor 2. The only other statistically significant trend is the decrease in median value for Factor 1 as the belief increases that equality of opportunities for minorities has not gone far enough. Overall, despite a few clear trend in responses to these political questions, there is no consistent pattern.

\section{Discussion}

Although changes in the frequency individuals undertake specific environmental behaviours can be related to their environmental world-view, it seems that a non-fatalist view of environment and its management is the key driver to carry out simple individual actions such as switching lights off. Factor 2 seems to be more important in prompting actions related to interacting with others be they companies producing packaged goods or to car share. Factor 2, the factor related to beliefs about the nature of our relationship to the environment, are stronger determinants of lifestyle intentions. Even so, the number of specific behaviours whose frequency or likelihood increases or decreases significantly with changes in individual factor scores is relatively limited. For environmental behaviours only four out of the ten behaviours show significant changes in factor scores with frequency or with likelihood and only two out of the five lifestyle intention show any significant pattern. Despite the beliefs about the nature of the environment and humanity, actual concrete actions to prevent environmental degradation are very limited. Simple individual acts such as switching lights off are more likely if an individual has a non-fatalistic view of environmental management but this does not extend consistently to other individual acts such has wearing more clothes when it is cold. Likewise, although there is a significant attempt to ensure packaging is considered before purchasing products the same acts of consideration are not made in relation to taking your own bag shopping, to walking or taking a bus or even to recycling paper. It seems that concerns about the environment are not sufficient in themselves to result in consistent actions to prevent environmental damage. This would suggest that other incentives or drivers are required to convert concerns into actions.

Turning to the wider context of political beliefs, there does seem to be some relationship between political world-views and the factor scores of individuals, but once again the pattern is not consistent. Increased intention to vote Labour are clearly associated with increasing Factor 2 scores and with what would be seen as key progressive political policies of believing NHS cuts had gone too far and with a belief in the need for income redistribution as well as a suspicion of big business. The belief in the need to manage the environment, to maintain it within identifiable limits to maintain its balance, is associated with these progressive policies. The relationship is not consistent, however, across all progressive policies. Belief that cuts in spending on education and public services in general have gone too far are not associated with increasing Factor 2 scores. Likewise, on issues such as welfare benefits, the fair share of rewards in society and the role of private companies there is no association between progressive political beliefs and increasing Factor 2 scores.

Increases in Factor 1 scores are associated with more conservative views but only in relation to the opportunities available to minorities having gone too far. For most other policies there is little change in Factor 1 scores with increasing or decreasing agreement with the statement presented. The key exception is to the question as to whether environmental protection has gone too far. Factor 1 scores decrease as responses to this question move towards the view that they have gone too far with Factor 2 scores increasing as responses move in this direction.

The results highlight the significance of viewing environmental concerns and environment actions as well as the gap between these, within the context of the individual and the wider society of which they are a part. The two views of the environment derived from factor analysis emphasize that even if individuals experience the same educational system where climate change is taught, their perception of the nature and magnitude of environmental issues is still mediated through their own filters formed by their political and socio-economic conditions. Concern for the environment is commonplace amongst this sample of undergraduates but their willingness to act on these concerns is rather less than universal. Even simple actions to prevent environmental damage are not undertaken and key lifestyle changes required now and in the future seem to be continually weighed against their own expectations for a successful life. Whilst the cultural beliefs framework used to derive factors is a useful device to classify views, the significance of the political filter on beliefs, as well as the complex and seemingly inconsistent nature of this filter is an area that could improve our understanding of the gap between environmental concerns and actions.

\section{Conclusion}

This research examined the environmental world-views of undergraduate students. In part it supports the research by Price et al. (2014) that simplified views of the environment could be classified into the environment as elastic and the environment as ductile. However, in contrast to Price et al. (2014) this research has found that the environment as elastic views are based on the fatalistic/non-fatalistic world-view of the group under investigation. It is therefore worthwhile dividing environmental groups into 'the environment as ductile or elastic' but as shown the basis of these world-views may be 
subtly different to previous research. In addition, this research has shown that there does not appear to be a clear-cut relationship between political allegiance and environmental actions.

This research has also shown that even with individuals with a non-fatalistic view of the environment that behaviours often do not move beyond the simplest of environmental actions. There as with other research appears to an inconsistency with environmental concerns and environmental actions. From a policy perspective, the findings of the research suggest that a one size fits all to influence environmental behaviour may be inappropriate and indeed ineffective. There is a need for further research not to further assess the inconsistency between views and actions but also to examine ways in how, if at all, this gap can be reduced.

Acknowledgements The authors would like to thank Dr. Julia Brown and Dr. Craig Duncan for their constructive criticism during draft versions of this paper. This research was undertaken with ethical approval from the University of Portsmouth and in compliance with the data management guidelines of the university.

Open Access This article is distributed under the terms of the Creative Commons Attribution 4.0 International License (http:// creativecommons.org/licenses/by/4.0/), which permits unrestricted use, distribution, and reproduction in any medium, provided you give appropriate credit to the original author(s) and the source, provide a link to the Creative Commons license, and indicate if changes were made.

\section{References}

Adger N, Barnett J, Brown K, Marshall N, O'Brien K (2013) Cultural dimensions of climate change impacts and adaptation. Nat Clim Chang 3:112-117

Barr S (2007) Factors influencing environmental attitudes and behaviors: a U.K. case study of household waste management. Environ Behav 39(4):435-473

Blake J (1999) Overcoming the 'value-action gap' in environmental policy: tensions between national policy and local experience. Local Environ 4:257-278

Cattell, R. B. (1966). The Scree Plot Test for the Number of Factors. Multivariate Behavioral Research, 1, 140-161

Coppock A, Green DP (2017) Do belief systems exhibit dynamic constraints? Working Paper https://acoppock.github.io/projectpages_ CG_dynamicconstraint.html

DEFRA (2008) A framework for pro-environmental behaviours. Available at: https://data.gov.uk/dataset/ab16e19f-a4e1-42e4-9f6e$5 \mathrm{fffe} 2 \mathrm{dc} 7680 /$ survey-of-public-attitudes-and-behaviours-towardsthe-environment. Accessed October 30, 2018

Dake K (1992) Myths of nature: culture and the social construction of risk. J Soc Issues 48(4):21-37

DeGroot JL, Steg L (2009) Mean or green: which values can promote stable pro-environmental behavior? Conserv Lett 2:61-66

Douglas M (1978) Cultural bias. Royal Anthropological Institute of Great Britain and Ireland, London

Douglas M, Wildavsky A (1982) Risk and culture: an essay on the selection of technical and environmental dangers. University of California Press, Berkeley, CA
Dunlap RE, Van Liere KD, Mertig AG, Jones RE (2000) New trends in measuring environmental attitudes: measuring endorsement of the new ecological paradigm: a revised NEP scale. J Soc Issues 56(3): 425-442

Eilam E, Trop T (2012) Environmental attitudes and environmental behavior - which is the horse and which is the cart? Sustainability 4:2210-2246

Hobolt SB (2016) The Brexit vote: a divided nation, a divided continent. Journal of European Public Policy 23(9):1259-1277

HM Government (2018) A Green future: our 25 year plan to improve the environment. OGL

Johnstone ML, Tan LP (2015) Exploring the gap between consumers' Green rhetoric and purchasing behaviour. J Bus Ethics 132:311-328

Jones, R. P., Cox, D. and Navarro-Rivera, J. (2014) Believers, sympathizers and skeptics. Why Americans are Conflicted aboutClimate Change, Environmental Policy, and Science. Findings from the PRRI/AAR Religion, Values, and Climate Change Survey. American Academy of Religion.

Kahan D (2010) Fixing the communications failure. Nature 463:296-297

Kahan DM, Braman D, Cohen GL, Gastil JW, Slovic P (2010) Who fears the HPV vaccine, who doesn't, and why? An experimental study of the mechanisms of cultural cognition. Law Hum Behav 34(6):501516

Kahan D, Peters E, Wittlin M, Slovic P, Ouellette LL, Braman D (2012) The polarizing impact of science literacy and numeracy on perceived climate change risks. Nat Clim Chang 2:732-735

Kollmus A, Agyeman J (2002) Mind the gap: why do people act environmentally and what are the barriers to pro-environmental behaviour? Environ Educ Res 8:239-260

Ledesma, J.L.J., Futter, N.M., Laudon, H., Evans, C.D. and Kohler, S.J. (2015) Potential for long-term transfer of dissolved organic carbon from riparian zones to streams in boreal catchments. Science of the Total Environment, 560-561, 110-122.

Lynn P (2014) Distinguishing dimensions of pro-environmental behaviour. ISER Working Paper Series, 2014-19, University of Essex (https://www.iser.essex.ac.uk/research/publications/workingpapers/iser/2014-19)

McCarty JA, Shrum LJ (1994) The recycling of solid wastes: personal and cultural values and attitudes about recycling as antecedents of recycling behavior. J Bus Res 30:53-62

Milfont TL (2007) Psychology of environmental attitudes: a crosscultural study of their content and structure. Unpublished doctoral dissertation, University of Auckland, Auckland

Milfont T, Duckitt J (2010) The environmental attitudes inventory: a valid and reliable measure to assess the structure of environmental attitudes. J Environ Psychol 30:80-94

Phillips D, Curtice J, Phillips M, Perry J (2018) British social attitudes: the 35th report. The National Centre for Social Research, London

Poortinga W, Spence A, Whitmarsh L, Capstick S, Pidgeon NF (2011) Uncertain climate: an investigation into public scepticism about anthropogenic climate change. Glob Environ Chang 21:1015-1024

Price JC, Walker IA, Boschetti F (2014) Measuring cultural values and beliefs about environment to identify their role in climate change responses. J Environ Psychol 37:8-20

Rhead R, Elliot M, Upham PJ (2015) Assessing the structure of UK environmental concern and its association with pro-environmental behaviour. J Environ Psychol 43:175-183

Schultz W, Gouveia VV, Cameron LD, Schmuck P, Franek M (2005) Values and their relationship to environmental concern and conservation behavior. J Cross-Cult Psychol 36:457-475

Schwarz M, Thompson M (1990) Divided we stand: redefining politics, technology and social choice. Harvester Wheatsheaf, London

Steg L, Sievers NV (2000) Cultural theory and individual perceptions of environmental risks. Environ Behav 32(2):250-269

Taras V, Kirkman BL, Steel P (2010) Examining the impact of Culture's consequences: a three-decade, multilevel, meta-analytic review of 
Hofstede's cultural value dimensions. J Appl Psychol 95(3):405439

Tavakol M, Dennick R (2011) Making senses of Cronbach's alpha. Int J Med Educ 2:53-55

Triandis HC (1996) The psychological measurement of cultural syndromes. Am Psychol 51(4):407-415
Whitmarsh L (2011) Scepticism and uncertainty about climate change: dimensions, determinants and change over time. Glob Environ Chang 21:690-700

WWF (2018) Living planet report - 2018: Aiming Higher. Grooten, M. and Almond, R.E.A.(eds). WWF, Gland, Switzerland 